\title{
Cultura de Paz, integración latinoamericana y universidades
}

\section{Propuesta de una línea de inves. gación}

A Alfredo Guerra Borges in memoriam

\section{Resumen}

El presente artículo contiene una justificación para establecer una línea de investigación interdisciplinaria sobre "Cultura de paz, integración latinoamericana y las universidades" que podría efectuarse por medio de una articulación entre universidades y centros de investigación de nuestro país, con el propósito de conocer y actualizar la información sobre las diversas instancias del proceso histórico de la integración de América Latina y de Centroamérica y en particular, capacitar a los futuros profesionales de las universidades para prever las alternativas de solución a los desafíos y problemas de estas realidades.

Palabras clave: Cultura de paz, integración regional, universidad.

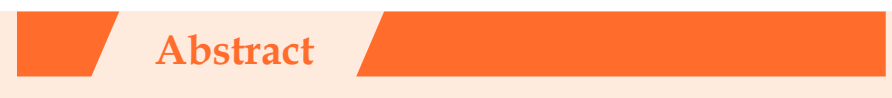

This article contains a justification for establishing an interdisciplinary line of research on "Culture of Peace, Latin American Integration and Universities", which could be carried out through an articulation between universities and research centers of our country related to the subject. This with the objective of knowing and update the information on the various instances of the historical process of Latin American and Central American integration, and in particular, future professionals be trained in universities in order to anticipate the alternatives to solve the challenges and problems of these realities.

Key words: Culture of peace, regional integration, university.
Cultura de Paz, integración latinoamericana $\mathrm{y}$ universidades son conceptos y realidades que se muestran en un juego de relaciones creadoras, pertinentes y actuales desde una óptica en que se ve a Latinoamérica como una comunidad de desarrollo y paz. En las universidades nicaragüenses, por ejemplo, la integración es una ausencia como parte de la formación de los profesionales o solo se aborda a nivel de formación postgraduada como un asunto tangencial de la historia, algunos de los académicos la ven como unideal imposible y los políticos como una retórica. Cuando en realidad se han vivido momentos de la integración real económica y política y el postulado debía ser que, a más desarrollo e integración, mayor paz para los diversos pueblos de nuestra América.

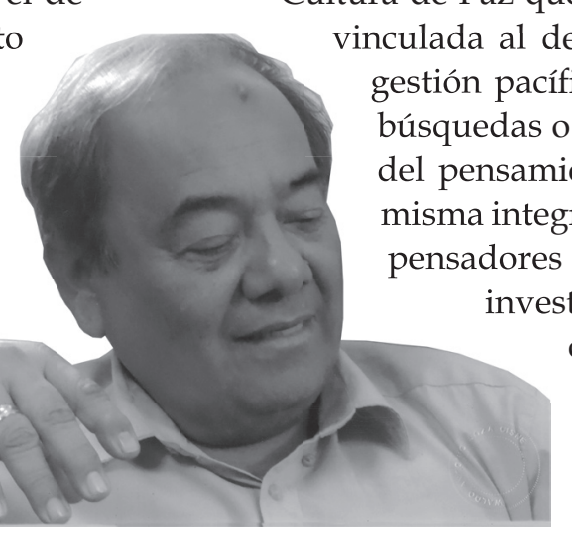

De ahí que veamos la necesidad e incluso, el deber de promover el conocimiento de nuestra realidad cercana: Latinoamérica. Y ello significa estudiar e investigar y promover un tema de importancia estratégica para nuestras sociedades como es la integración latinoamericana en sus dimensiones económica, política, jurídica, cultural desde la perspectiva de una Cultura de Paz que es una cultura política democrática, desarrollo humano y sostenible y a la de los conflictos. Además, estas
vestigaciones deben incluir el tema ento político latinoamericano de esta gración que subyace en los textos de los latinoamericanos, los académicos e tigadores del tema en esta vasta región que espera todavía un proyecto de desarrollo plural, democrático $\mathrm{y}$ pacífico, sin dictaduras $\mathrm{y}$ sin imposiciones.

1 Docente Investigador del área de Educación para la Paz y los Derechos Humanos. Instituto de Investigaciones y Acción Social Martin Luther King. Universidad Politécnica de Nicaragua (UPOLI) e mail: erwinjotasil@gmail.com 


\section{Cultura de Paz}

Como se sabe, cultura de paz es un nuevo paradigma de la convivencia y la solidaridad humana que fue creado precisamente, en América Latina por Felipe Mc Gregor, quien lo usó y lo definió frente a la cultura de violencia. De tal manera que esta nueva concepción de la cultura y de la paz resultó estar profundamente comprometida con el esfuerzo de no usar la violencia para la solución de los conflictos.

Cultura de paz tiene todo un desarrollo histórico normativo que se inicia precisamente en 1989 con la Declaración de Yamusukro, Costa de Marfil, África.

El documento clave de la evolución del concepto de Cultura de Paz, una vez integrado el concepto a los documentos de la Organización de las Naciones Unidas (ONU), es la Declaración y Programa de Acción sobre una Cultura de Paz (A/RES/53/243) del 6 de Octubre de 1999, Asamblea General de la ONU.

En este instrumento de las Naciones Unidas, de carácter universal y comprensivo se destaca la definición misma de Cultura de Paz que es:

Un conjunto de valores, actitudes, tradiciones, comportamientos y estilos de vida basados en el respeto a la vida, el fin de la violencia y la promoción y la práctica de la no violencia por medio de la educación, el diálogo y la cooperación.

Pero igual se resaltan otros conceptos, instrumentos y acciones, tales como:

- el respeto pleno a la soberanía e independencia política de los estados.

- el principio de no injerencia los asuntos de los estados.

- el arreglo pacífico de los conflictos.

- la promoción de los derechos humanos.

- los esfuerzos para el desarrollo y la protección del medio ambiente.

- la promoción del derecho al desarrollo.

- la adhesión a los principios de libertad, justicia, democracia, pluralismo, diversidad, solidaridad, diálogo, cooperación, entendimiento y paz.
Todos estos conceptos, principios, valores y prácticas son elementos y componentes necesarios para una comprensión distinta de la integración latinoamericana y convocar a los investigadores, intelectuales y pensadores de comunidad académica para que estudien, promuevan y planteen soluciones y propuestas sobre el tema predicho en el espacio de la Universidad Nicaragüense.

\section{Integración}

Indudablemente, el abordaje y la realización de investigaciones sobre la integración latinoamericana es impostergable, porque esta avanza de alguna manera y es real que existen ya MERCOSUR, la Alianza Bolivariana de las Américas (ALBA), la Comunidad de Estados Latinoamericanos (CELAC), solo para citar las herramientas de integración económica y política de la última década. Por lo que las universidades nacionales no pueden quedarse al margen viendo correr la historia cuando incluso, Nicaragua es parte ya de estas instancias del proceso integracionista como son el SICA, ALBA y ALIDES. Además, se impone ética y políticamente, la necesidad de introducir en al ámbito académico el conocimiento de los distintos proyectos que existen, porque nos movemos y nos interrelacionamos en el mercado, en la cooperación, en el comercio y la transacción de la información de la economía, la política y la cultura latinoamericana.

La integración latinoamericana con todos sus logros, fracasos y desafíos es una experiencia única pero, inacabada que tiene sus orígenes en los tiempos de la Independencia de América Latina. En los años de nuestra liberación del imperio español, la Integración era un ideal bolivariano y podemos decir que en cierto modo, permanece. Algunos como Álvaro de la Ossa (1999) al respecto de la integración centroamericana, la vieron fenecer y renacer en los años 80 y 90 . Sin embargo, hoy en día la integración es un proceso real para solventar nuestro déficit histórico en materia de unidad y las crisis que vivimos y las que se vislumbran en nuestro horizonte. $\mathrm{O}$ sea, se ha pasado de la retórica a los hechos y es perentorio que abordemos primero lo regional, sin obviar la universalidad o la realidad de la globalización.

Si solo examináramos los últimos sesenta años de la evolución histórica de la 
integración regional, por ejemplo en Centroamérica, una subregión afectada más bien por las guerras civiles y la desintegración desde 1838, cuando comenzó la disolución de la Federación Centroamericana, nos daríamos cuenta de cuántas lecciones podemos aprender de ese pasado de la integración y de cuanto futuro les espera a nuestros países si seguimos la ruta de la unidad y de la integración efectiva en un bloque centroamericano que contribuya a la consolidación de una América Latina, camino de su unidad y en una posición influyente en este mundo globalizado.

En la actualidad existe un cierto desarrollo jurídico e institucional en Centroamérica con miras estrictas a la integración centroamericana, tales como el Sistema de Integración Centroamericana (SICA), la Corte de Justicia Centroamericana (CCJ), pero no todos formamos parte del concierto de la nación única y de estas superestructuras. Existen, por ejemplo, acuerdos aduaneros, migratorios, de seguridad, de medio ambiente mas no todos los estados forman parte de la unión centroamericana que deberíamos ser bajo el signo de una paz positiva y democrática.

Como una referencia relativamente reciente se han firmado también una Alianza para el Desarrollo Sostenible (1994) y un Tratado Marco de Seguridad Democrática en Centroamérica (1995), que constituyen hitos en el desarrollo del componente ambiental de la integración y de seguridad en el contexto de las democracias de nuestra región.

\section{Universidades}

La integración latinoamericana se corresponde con la historia política y económica y éstas son parte de las disciplinas que se pueden estudiar e investigar en las universidades latinoamericanas y nicaragüenses. Uno de los temas que vincula el curriculum universitario y los procesos políticos en Latinoamérica es precisamente, el de la integración regional. En muchas universidades latinas existen los estudios latinoamericanos y caribeños de postgrado, incluso, hay plataformas educativas virtuales para la integración regional, lo mismo que Cátedras y Centros de Investigación desde donde se propicia el conocimiento, pero este desarrollo académico es desigual y las instituciones y los órganos de integración en algunos países continúan siendo desconocidos, porque

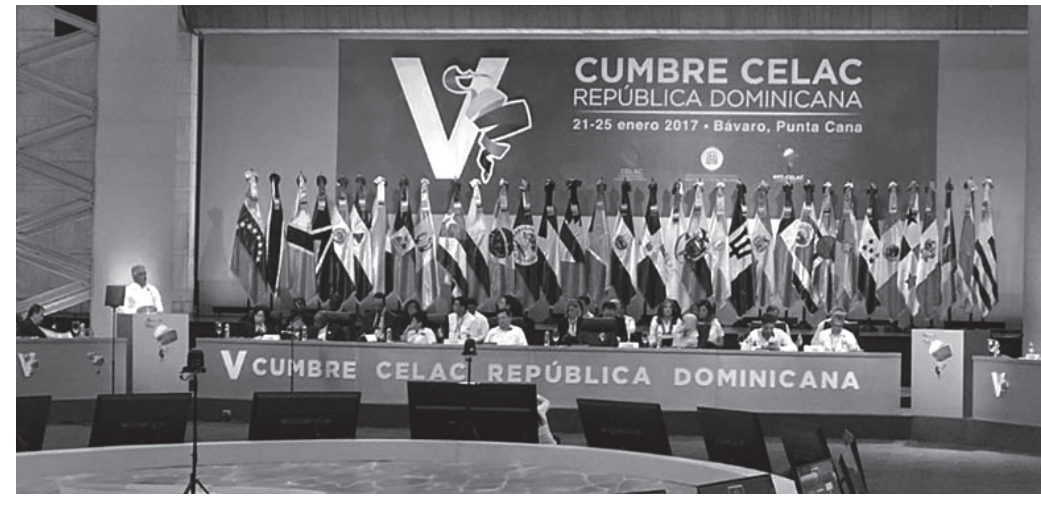

nuestra mirada está puesta en Europa o Asia y no nos vemos ni nos estudiamos a nosotros mismos.

De tal manera que es posible, por medio de estudios e investigaciones de carácter regional con base en las universidades del continente, interactuar y conocer mejor y cada vez más del proceso histórico de la integración latinoamericana. Esto puede hacerse sin caer en dogmas ideológicos o metodológicos, propiciando el pluralismo epistemológico.

Jacques Delors dice de las potencias que encierra la educación cuando se sostiene sobre pilares tales como el aprender a aprender y el de aprender a convivir, pero en relación a la universidad que debe ser reformada se la ve en el informe titulado "La educación encierra un tesoro" como:

Lugar de ciencia y fuente de conocimiento que llevan a la investigación teórica o aplicada, o a la formación de profesores. (1996:27)

Las universidades de nuestra América son los espacios de creación del conocimiento y de la investigación, por tanto, el conocimiento y la investigación científica pueden y deben ser herramientas de gestión para el desarrollo humano en su expresión local, nacional o regional, de la solución de los numerosos problemas que nos aquejan tales como la pobreza extrema de la que todos hablan pero su lenta disminución se ha convertido en una vergüenza y un enorme desafío para la paz y la gobernabilidad.

La nueva misión de la Universidad es salir a la palestra pública y convertirse no solo en el lugar de la respuesta a los problemas regionales sino ser un actor creativo de la integración con miras a la eliminación 


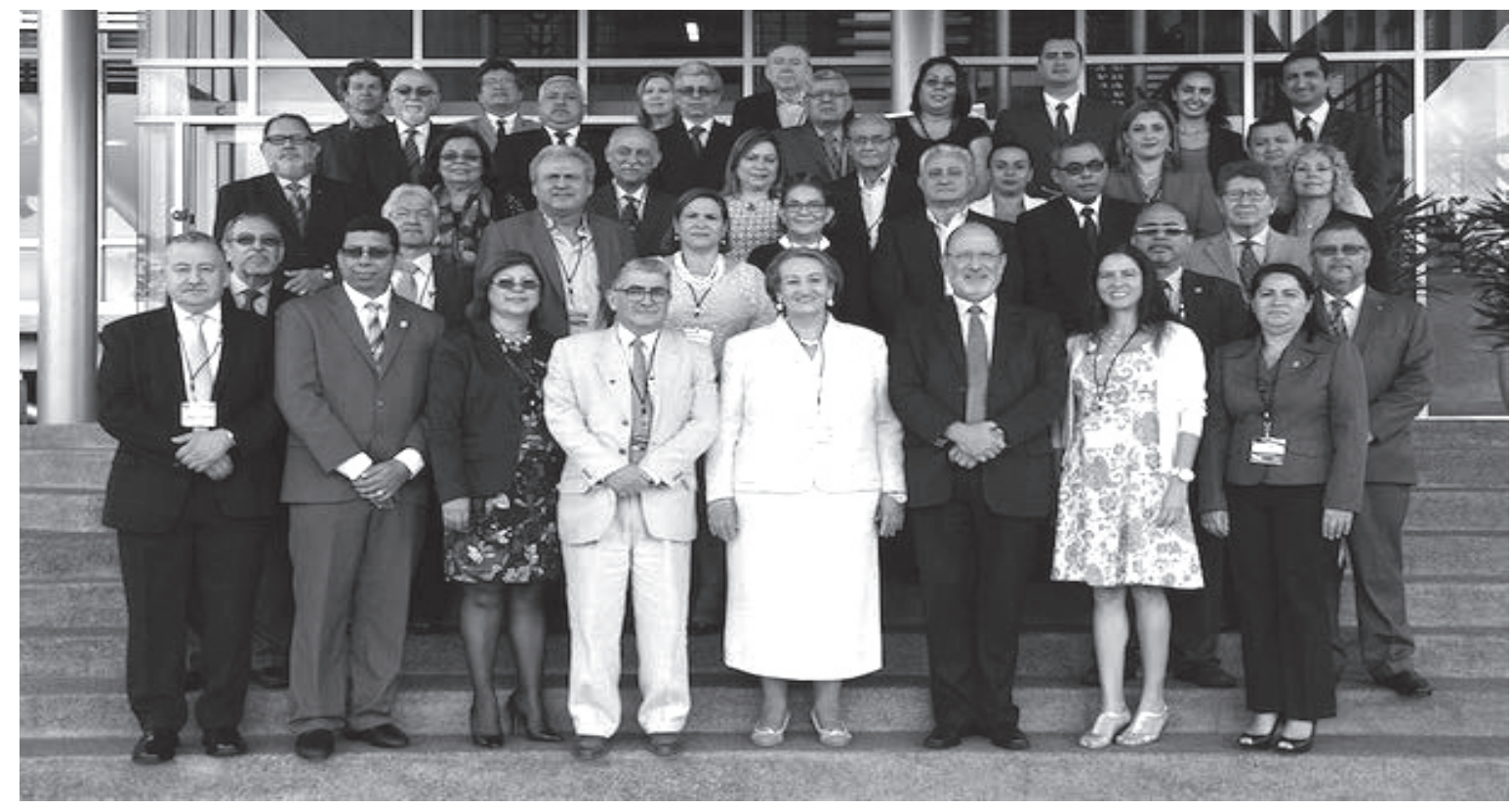

V. Asamblea Regional Centroamericana de la UDUAL. Colaboración Universidad de Costa Rica (UCR).

de todas las asimetrías entre nuestros pueblos. Las universidades latinoamericanas incluida la nicaragüense, deben superar ese perfil de centros de adiestramiento reproductivo de profesionales con el afán de rentabilidad o meramente de suministro de recursos calificados y certificados para los sectores económicos locales sin vistas al horizonte latinoamericano actual.

Una parte del futuro de las universidades nicaragüenses es que la integración sea parte del porvenir de estas instituciones de educación superior, que promuevan la interculturalidad, la cultura de paz y la cultura ecológica como se contempla en la visión de Carlos Tünnermann Bernheim. Este autor agrega que la universidad deberá ser:

Una universidad que promueva la integración regional pero que, a la vez, incorpore en su enseñanza una visión holística del mundo, auspicie una comprensión entre las naciones y asuma, resueltamente, la dimensión internacional que hoy día tienen el conocimiento, la información y la propia educación superior (2011:84).

Una de las misiones de la universidad latinoamericana es ser gestora de la unidad nacional latinoamericana con fundamento en la identidad cultural de nuestros pueblos y, por ello, instituciones propiciadoras de nuevos diseños del desarrollo. La cultura y sus códigos nos identifican o pueden hacer en nosotros cambios para evolucionar en la conciencia, la sociedad y la historia. Recordemos con Edgar Morin que: “La cultura está constituida por el conjunto delos saberes, saber hacer, reglas, normas, interdicciones, estrategias, creencias, ideas, valores, mitos que se transmite de generación en generación" (1999:28).

Por eso es que la nueva matriz de los valores de la Cultura de Paz ya explícitos en los instrumentos jurídicos internacionales, como la tolerancia, la democracia, la igualdad, el pluralismo político y la interculturalidad son bases justas para pensar que la universidad como entidad del conocimiento conjugue estas realidades y pensamientos y se dé a la tarea de crear integración conociendo primero el fenómeno y conduciendo luego a los pueblos a una integración en la libertad como quiso Simón Bolívar. ${ }^{2}$

Recordemos que hay valores fundacionales de la integración latinoamericana como la unidad, independencia, soberanía, libertad y la justicia. ${ }^{3}$

2 Zea, Leopoldo. Bolívar integración en la libertad. Monte Ávila Latinoamericana. Caracas,1993

3 Colectivo de Autores.Los valores fundacionales de la integración latinoamericana. Editorial Feijoo,2009.p.42 
La Universidad puede mover a la sociedad hacia: "la comprensión, la tolerancia y la solidaridad entre todas las civilizaciones, los pueblos y las culturas, incluso hacia las minorías étnicas, religiosas y lingüísticas (...) con respeto pleno a la autodeterminación de los pueblos."4

Los nuevos temas de la integración y las versiones de ésta exigen y proporcionan a la vez un vasto material de estudio que posibilitan nuevas investigaciones de la realidad de América Latina.

\section{BIBLIOGRAFIA}

De la Ossa, Álvaro (1999). La unión centroamericana: condiciones y perspectivas. CRIES, Managua.

Zea, Leopoldo (1993). Bolívar la integración en la libertad. Monte Ávila Latinoamericana, Caracas.

Colectivo de autores (2009). Los valores fundacionales de la integración latinoamericana. Editorial Feijoo, La Habana.

Delos, Jacques (ed.) (1996) La educación encierra un tesoro UNESCO.

Tunnerman Bernheim, Carlos. (2011). La universidad del futuro. Managua, HISPAMER.

Morin, Edgar (1999). Los siete saberes necesarios para la educación del futuro. París, UNESCO.

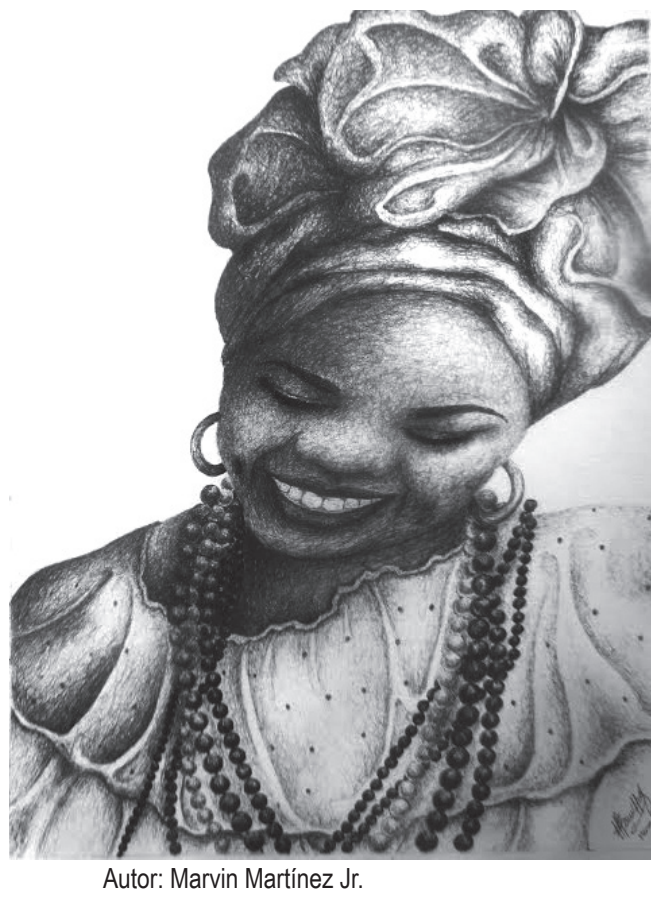

INFORMACION PARA UNA LINEA DE INVESTIGACION

\author{
Nombre de la línea:
}

Cultura de Paz e Integración

Latinoamericana

\section{Justificación de la línea:}

- En los Estatutos de la Universidad Politécnica de Nicaragua (reformados en el año 2010) se contempla la cultura de paz dentro de la Misión, Capítulo II. Artículo 4. Capítulo III. Visión Arto.5 (f) también el Capítulo IV. Fines Articulo 6 (e y f). así mismo en el capítulo $\mathrm{V}$, de los principios fundamentales; (a) sobre la preeminencia de los valores cristianos, éticos y morales y el inciso (f y g).Encontramos igual que la Política Institucional de Género, se tiene como un compromiso la promoción de una cultura de paz.

- La Cultura de Paz es una asignatura para todas las carreras profesionales de la Universidad Politécnica de Nicaragua. Además se constituye como un Eje Transversal que atraviesa todo el curriculum de las carreras profesionales de la UPOLI.

- La Universidad Politécnica de Nicaragua (UPOLI, 1967) es parte del sistema nacional de la educación superior de Nicaragua. Es Miembro del Consejo Nacional de Universidades (CNU).

- La universidad nicaragüense es parte de las universidades latinoamericanas que tienen en muchos casos, orígenes comunes en la historia y la cultura de América Latina.

- La universidad nicaragüense por su contexto, su historia y un proyecto común tiene una vocación de integración.

4 ONU (1999).Declaración y Programa de Acción sobre una cultura de paz. A/RES/53/243. 
- Nuestro contexto vital y geo cultural es Latinoamérica, de la que Nicaragua es parte integrante y además se inserta en un determinado modo de existir social, económica y políticamente, cuya raíz e identidad tiende a la unidad y la integración latinoamericana.

- Nicaragua es parte también de una historia y de un pensamiento político común que ha experimentado a lo largo de los siglos de vida independiente y ha defendido la unidad latinoamericana.

- De igual manera, ha experimentado la unidad centroamericana en el siglo XIX, siendo parte del proyecto federal unionista de 1823 a 1838, en que se funda el primer estado nacional.

- En la mayoría de las Constituciones Políticas de Nicaragua, se sostiene la unidad centroamericana como vocación, aspiración y proyecto.

- En los años sesenta del siglo pasado, Nicaragua fue parte integrante del Mercado Común Centroamericano y en la actualidad es miembro del Sistema de Integración Centroamericana (SICA) y mantiene un acuerdo denominado el C-4. Además Nicaragua es estado parte del Parlamento Centroamericano (PARLACEN) y reconoce la funcionalidad de la Corte Centroamericana de Justicia (CCJ).

- También es socio en el tratado de comercio con la Unión Europea (UE).

- Nicaragua es miembro de la Comunidad de Estados Latinoamericanos y del Caribe (CELAC).

- Aparte de una de una geografía compartida con nuestros hermanos de Centroamérica, los nicaragüenses tienen una geografía, recursos naturales compartidos, cultura y en cierto sentido una historia política común con éstos y que parte de momentos de dependencia, sojuzgamiento de imperios y experiencias de liberación así como las vías a la democracia y la paz.

- La democracia es una clave de la paz y el desarrollo en Centroamérica.

- La construcción de la democracia, el desarrollo y la paz tienen como una condición indispensable la integración, de modo que todas estas interrelacionadas contribuyen a construir una cultura de paz.

\section{Objetivos}

- Interrelacionar las disciplinas que concurren en la Cultura de Paz en un grupo de investigadores que se constituya para tales temas.

- Constituir como un tema de estudio interdisciplinario de la Universidad Politécnica de Nicaragua (UPOLI), la integración latinoamericana en todas sus dimensiones.

- Realizar estudios e investigaciones relevantes sobre el estado actual y las bases de la integración latinoamericana.

\section{Sublineas:}

- Experiencias actuales de la integración latinoamericana.

- Integración Centroamericana: económica, política, social, jurídica y cultural.

- Pensamiento político de la integración y unidad latinoamericana. Unionismo. Bolivarismo.

\section{Temas asociados a la Línea:}

- Evolución institucional de la integración latinoamericana.

- Desarrollo normativo de la integración latinoamericana y centroamericana.

- Integración económica de Centroamérica

- Integracióny desarrollo sostenibleen Centroamérica

- Las ideas políticas y la integración en Centroamérica.

- Integración y diálogo intercultural.

- Integración social en Centroamérica, limitaciones y oportunidades para el avance.

\section{Disciplinas y paradigmas:}

- Derecho, Economía, Administración, Antropología, Sociología, Ciencias Políticas, Historia, Estudios de Paz y Teoría de Género, Cultura de Paz y Desarrollo Sostenible. 